\title{
Changing Media Space and Evolution of Digital Culture.
}

\section{Irfan Ahmad}

\section{Jawaharlal Nehru University New Delhi, India.}

\begin{abstract}
:
This paper tries to provide a brief analysis of the history of changing media space and the evolution of digital culture, with a special focus on the comparative analysis of pros and cons. It highlights the power of new media and that how it helps institutions, government apparatus and the scientific communities, for example, universities in making a participatory environment among citizens and in the dissemination of knowledge and scientific thoughts in a best possible way. In addition, it also provides opportunities to learn with peers without geographical boundaries famously known as: Peer-to-peer learning and helps to develop new skills required in the modern age. But at the same time there are some concerns that need for policy and pedagogical interventions like participatory gap, Transparency and ethical challenges. This is the problem statement of this paper.
\end{abstract}

الملخه::

$$
\begin{aligned}
& \text { سيحاول هذا المقال أن يقدم تحليلا وجيزا في مساحة وسائل الإعلام المتغيرة عبر } \\
& \text { التاريخ وتطور الثقافية الرقمية مع التركيز على الدراسة المقارنة في الجانب الإيجابي والسلبى } \\
& \text { ويلقى الضوء على قوة وسائل الإعلام الجديدة وعلى أنه كيف يساعد الميئات والمؤسسات } \\
& \text { الحكومية والدوائر العلمية مثلا الجامعات في جعل بيئة تشاركية فيما بين السكان في نشر العلوم } \\
& \text { والمعرفة بصورة أحسن وبأسرع وقت ممكن وفي توفير الفرص للتعلم مع الأقران بلا حدود } \\
& \text { الجغرافية ما يقال: Peer-to-peer learning وتنمية المهارات الحديثة المطلوبة في عصر } \\
& \text { الحديث. ولكن في وقت نفسه هناك بعض الاهتمامات تحتاج التدخلات السياسية والتربوية } \\
& \text { مثلا تعبية الفجوة التشاركية، الشفافية، والتحديات الخلقية. وهذه هي إشكالية هذا المقال. }
\end{aligned}
$$




\section{Introduction :}

We're living in a fast moving world where the pace of the cycle of innovation and obsolescence is extremely rapid. There was a time when people used to rely solely on their robust memory power for oral narratives in sharing ideas, information, data and knowledge. The realization that the volume of knowledge is increasing exponentially over and above the capacity of human memory led to the invention of method of writing, in particular the use of the alphabet. This was a major milestone in the history of mankind and played a seminal role in the progress of human society.

This new means of communication provided the capacity to store and transmit information over space and time: Space, as writing could be transmitted from one place to another and Time, as writing could preserve the words for generations to come (Archaeology Expert, 2008).

The invention of writing systems and evolved narratives necessitated the search for means of writing and preservation for future generation and this trajectory was traversed from writing on stone to paper. The dawn of the printing press and paper technology was regarded as being a major breakthrough due to its lightness and ease of portability. People used it to note, register, measure, account for, classify, authorize, endorse and generally to tot up, gee up and make their lives good. Apart from this, paper also played a crucial role in making human economies, easing trade operations by printing 
banknotes for money and recordkeeping, paper laws propped up in the governments, paper maps divided lands and paper books helped shape people's minds. In concise, it wouldn't be wrong to say that entire civilizations were built on paper (Ian Sansom 2012). The printing press remained one of the last true revolutions in developing new innovative narratological approaches and content management system; a true milestone that enabled the unlimited reproduction of texts at limited cost and gave a new horizon to various sorts of narratives.

The historical advent of hypertext and the World Wide Web in late 1990s opened up a whole new world of possibilities for scientists and thinkers to interlink electronic texts and share them with others online and the idea of marrying a physical book or any other written material on paper for example; letters, brochures, articles, mails and all with the machine on screen in the form of Ebook, Email, Epaper and Epub as conceived by many in eighteenth-centuries got strong support. Hence the whole ecosystem of digital culture and digital narratives emerged.

With this, the past couple of decades have seen a virtual revolution in information technologies and their mobilization in the fields of communication and entertainment. The advent of the internet and the subsequent shrinkage of the online space into what is termed as the global village have changed the way we communicate and do business with each other and also in the way we entertain ourselves. This revolution in information storage and communication technology 
has enabled shrinkage of data storage cost to previously unimaginable levels. For instance all of the books ever created can be stored at the cost of a few thousand dollars. Also computing devices have shrunk both in size and cost not to mention the previously unimaginable bandwidths available for commercial data transfer. This has made information and education available to a large section of the population.

Asian and African societies are among the countries going to have the highest internet penetration in the world in future because of their high volume of population, and with smartphone technology becoming cheaper and with cheaper tablets coming onto the market, for example the government of India's initiative of cheapest tablet Akash costing less than $\$ 25$, this truly has given enormous potential for greater sharing of knowledge and virtual space. Consequently, people are employing different modern tools and techniques to tell their stories. So the dynamic changes in digital culture are inevitable because of the dynamic changes in media spaces or in a precise context, devices.

Publishing industries and media houses are also getting more creative and willing to migrate from the traditional print world in favor of online dynamic world of publishing, where the possibilities of interactive content sharing and intelligent data manipulation are very powerful. This research paper will try to explore the opportunities of digital culture for people particularly the youth, the new generation. 
And also highlight the concerns such as participation gap, transparency and ethical challenges (Henry Jenkins-1958) and possible ways to balance according to the needs of the modern world. Parallels exist between physical world (what is there in our everyday life) and the digital world (also known as virtual spaces, what is there in cyberspace).

And how the rules and regulations which are applicable in our daily life are equally applicable in Cyberspace. Because with the passage of time the demarcation line between real life and virtual life is getting blurred (Mathew Ingram 2012). That's why we see that the government agencies and organizations have to employ the same rules and regulations to monitor the virtual sphere as they do with physical world, as the same nature of crimes and frauds are also happening over there.

When looking at the digital culture, one important development as Gustavo says is a shift in the association between youth and media. Youth are now active participants and playing very important roles in creating media content. Latest version of Web 2.0 and constantly reducing technology prices has given them greater opportunities (Gustao Mesh 2009). Now young bloggers using Wordpress and Google's Blogosphere are narrating their own stories and self-publishing them without having to go to big publishing houses. Photographers, musicians showcase their creativity on Adobe Behance, MySpace and Flicker etc. Now YouTube gives opportunity 
to us to run our own online channels. There are other players like SnapChat, WhatsApp, Pintrest, Tumbler, ZingMe, YouMob, Yookos, Yardbarker, Yammer, Wykop, WindowsGadget, Websahre, Webnews, Reddit, Quora etc. are providing different flavors to their online experience. At a time when digital communication systems have become the very part and parcel of modern daily life and have replaced traditional systems, it has become one of the very important areas to do research on. Hence the possibilities for making digital experience more conducive and valuable are very high.

\section{Method:}

The type of research method that will be used in this study is qualitative. With the help of basic descriptive ethnographic research method, it will mostly work with primarily unreconstructed data and explore social phenomenon. On a high level there will be two pronged approach of this paper, evolution of challenges and opportunities and providing suggestions for some best possible solutions:

\section{A. Challenges:}

Apart from some common challenges, faced by modern society, are decline of morale values, dehumanized professionalism, selfishness or being self-centered, over dependence, alienation, isolated intellect and exposure to huge amount of illicit contents like multimedia pornography, online sex, online pedophilia, push content with limited ability of parental control, cyber bullying and instances of other socially ill elements like cyber fraud, cyber hacking, cyber threat 
and all. In a lighter way wastage of too much time on chatting and surfing social networking sites or having cyber relationships creates a lot of health complications. Digital culture has also brought others particular social, psychological and technical challenges for modern societies.

Some of them are as follow:

\subsection{Psychological challenges:}

\subsection{Internet Addiction}

It is being commonly recognized by psychiatry professionals and psychology experts that a form of addiction exists where the user is "hooked" onto "being online" in both surfing Internet content as well as social media participation. The most interesting fact with regard to this is that this form of addiction is extraordinary similar with regard to effects on brain chemistry in terms of release of pleasure chemicals like dopamine among others in common with substance addiction.

The user too often suffers anxiety attacks and withdrawal symptoms not to mention psychological depression when forced due to circumstance to abstain from his "drug of choice". More and more research is coming out with regard to this in Western circles. Asian and African societies, having far less individual freedoms therefore incentivizes greater vicarious participation due to lack of avenues for such forms of entertainment in the environment around the concerned 
individuals. This actually may make such addiction more acute. More research needs to be done on this aspect.

\subsection{Substance addiction and Party Subculture}

With a huge influx of pop culture, social media participation may at times promote disco and party scene subculture wherein youth would like to go to pub, parties and all for fun that expose them to a lot of corrupting elements and ultimately lead to substance addiction like alcohol and drugs. And when in some stage they wouldn't be able to afford them they tend to resort to crimes, theft robbery etc. That's considered as one among the reasons we see the increasing graph of drug addiction among Asian and African youth.

\subsection{Creation of unrealistic materialistic aspirations}

Contemporary culture is often organized around a materialistic aspirational base where luxury goods are fetishized and seen as the ultimate experience to be achieved. Often such aspirations are unrealistic in terms of affordability for the vast majority of people. Also like any other material good, once possessed, it often loses its charm quickly. Many often at times, youth are compelled to resort to a life of crime to fulfill this level of aspiration. The failure of the commodity to satisfy the heightened level of expectations drives many an urban youth to suicide or a life of abject misery.

\section{$1.4 \quad$ Promotes jealousy, rivalry and infidelity}

Instances of suicide, quarrels and development of psychological complications are on rise in tech savvy Asian and 
African youths. Excessive freedom coupled with availability of social media resources and other modes of communication can at times cause the youth to stray down the path of marital infidelity and multiple extra marital relationships that end up in the form of rivalry and jealousy with each other. So, instead of working for worthy causes they are involved in trivial and often harmful pursuits.

\section{Social challenges:}

\subsection{Digital literacy and Participation Gap}

There's an acute absence of digital literacy in some marginalized societies particularly living in far flung areas where internet penetration is almost nil. This creates a digital divide for those who access it and for those who don't have opportunity to access it. And this gap plays an important role in creating an unbalance society, wherein families and children who are not connected to the digital world often falls behind and many cases never catch up (Philadelphia Mayor John Street). As a 2005 report on children's online experience in the United Kingdom conclude,

No longer are children and young people only or even mainly divided by those with or without access, though "access" is moving target in terms of speed, location, quality and support, and inequalities in access do persist. Increasingly children and young people are divided into those for whom the internet is an increasingly rich, diverse, engaging and stimulating resource of growing importance in their lives and those for whom it remains a narrow, un-engaging, if 
occasionally useful, resource of rather less significance (Sonia Livingstone and Magdalena Bober).

\subsection{Spreading rumors and misinformation}

The internet is a very powerful tool of communication in the modern era and its reach far overarches that of traditional media sources. Additionally, this channel of communication allows unregulated use by multiple senders and receivers. In addition to which, it is possible to amplify and echo a certain message, distorted from reality as it maybe by certain vested interests for their own nefarious purposes. This brings into the limelight again with regard to the regulation that is needed to promote social order.

\section{$2.3 \quad$ Excessive freedom and Individualism}

According to Manuel Castells: Around the world, the opposition between communalism and individualism defines the culture of societies as identity construction works at the same time with materials inherited from history and geography and from the projects of human subjects. The culture of communalism roots itself in religion, nation, territoriality, ethnicity, gender, and environment. The culture of individualism spreads in different forms,

-As market-driven consumerism,

- As a new pattern of sociability based on networked individualism, and

- As the desire for individual autonomy based on self-defined projects of life (M. Castells - .(2007 
Since, this whole new media phenomenon is a western thing invented by these people to fulfill their need and requirement. So, all the characteristics of freedom and individualism have been intelligently incorporated. Obsessive freedom and militant individualism presents an unbalanced self-centered world view that's inimical to both the individual and the society.

\subsection{Sensationalization}

With the advent of this form of media, rival groups generally use this to defame genuine religious personalities and authorities to weaken them and create a chaos among their followers. Often doctored photos or morphed video clippings are generated using modern photo or multimedia editing software like Adobe Photoshop, premier pro and Adobe edge and circulated among their followers through social networking sites.

\subsection{Receding Local Traditional Narratives}

The emerging digital culture has brought a whole new set of modern globalized vulgar narratives that presents a big threat to wipe out or at least weaken our traditional Asian and African narratives. Internet memes are very good example for this. Like YOLO, (You only live once) encourage a sensual lifestyle devoid of moral values with an emphasis on ephemeral pleasure.

\section{Technical challenges}

\subsection{Linguistic and Cultural Barriers:}


Since developed countries always attract modern multinational companies and big tech giants to do investment in research and development of tools and technologies for them. Often developing countries are left behind because of them being different in language and culture. Hence there are a lot of linguistic and cultural barriers that block them to use modern upcoming technologies.

\section{B) Opportunities}

In an age characterized by Marshall Mcluhan famously as: "Medium is message" (McLuhan 1964), it's paramount to understand the importance of new media or digital culture and the kind of opportunities it provides. Since a significant number of populations have already embraced this culture, it's very important to explore the available opportunities out of it.

Some of the best opportunities of evolving digital culture are: Through this medium we can connect to the like-minded people spread out all over the world and coordinate with them very easily on various social and cultural issues. We can target special audience and reach them with special contents. Developing countries from Asia and Africa have a rich syncretic cultural heritage having been fed from various sources over the decades. With the colonization process they were left scattered from its glorious past to the struggling present. Now digital technology has the potential to bridge this gap. The culture of other developed societies for example: Europe and America 
has flourished a lot because of digital revolution, consequently, we see a lot of influence of western culture in our daily life, the glamorous western narratives in advertisements of Pizza, Macdonald and Hollywood, often overarch our local narratives and covertly force us (new generation particularly youth) to adopt a globalised culture. For instance, the way we shop and celebrate birthday parties are influenced by new narratives of advertisement flocking from the west. Adaptation of others culture is not bad at all as long as they have positive moral impact matching with traditional local values. But when it is being adopted on the cost of local culture being diminished, it is really hazardous. Plus the era post colonization has also seen a fall in the usage of our local rich languages because of many reasons. So now, it's the need of the hour that narratives of eastern culture influenced by the traditional values should also take the advantage of digital technology like their other counterparts in Europe and America did and flourishes in the same way. Fortunately, the technology providing multinational companies have also recognized the need and potential of these local Asian and African markets and put their efforts in localizing their products for these markets in their native languages. Hence a little effort from our side also in adaptation, localization and vernacularization of technology can be a big step in this regard to promote local narratives on a global stage through modern communication technology.

The advent of electronic retailing has also thrown open enormous opportunities for allowing publishing on a far smaller scale 
with lesser sunk costs ensuring that amateur authors are not disadvantaged in reaching a target audience. In some sense, both the reading public as well as the writing community is enabled to connect with each other breaking the monopoly of large publishing houses. Google Ideas is an excellent initiative in this regard. This form of technology is ideal for local narratives, users will be able to meet an existing need which publishers have hitherto not been able to cater, as the focus remains on profitability and larger markets or in particular the market for writing commercial stuffs in English.

Marginalization of a language is concurrent with exclusion of the community which communicates in it. There are plenty of studies done by the governments in this regard, particularly the UN organizations reports. Therefore harnessing the power of digital technology to bring the wider world of information and local knowledge to these languages and vice versa can only serve as an extremely powerful tool of empowerment of the respective communities. The answer to combating backwardness is not to turn your back to technological innovation and consequently the future. Rather than this Luddite notion, the direction for progress is to move forward and embrace the technological change. With the advent of the revolution in information technology, there is no reason why one must see one language as threatening the existence of another. Technology with its lowering of costs can allow for the harmonious coexistence and mutual enrichment of both. The governments and other administrative agencies have acknowledged this in various policy 
frameworks and initiatives and they are setting up of boards for promotion of digital technologies in local languages and cultures to promote local narratives on a global scale.

\section{C) Best Possible Solutions}

\section{Democratizing Technology and Filling the linguistic and} Cultural gap.

As mentioned before in the introduction part; the advent of cheaper, more powerful and greater mobility in computing instruments along with pervasive connectivity have ensured the advent of ubiquitous computing in large parts of the world. Hence Technology (Digital devices along with internet) should be considered as basic right of every individual citizen and should be provided like food and water. The propagation of major oriental literatures that are mostly in Indic, Arabic or other sister languages like Urdu, Farsi, Dari, Kashmiri, Jawi and all on diverse platforms have brought with it greater technical linguistic challenges. The challenges today include the development of linguistic tools like thesaurus, dictionaries, translation $\&$ interpretation, text analytics, etc. The advent of the epub technology in digital publishing was specifically to address such challenge. Epub technology with its fluid liquid layout ensures that the same digital document is rendered readable on diverse platforms irrespective of the reading device being a smaller smart-phone screen, tablet or laptop and computer. Hence, authors, artists and writers have greater opportunities to employ different techniques to incorporate the 
benefit of all media; audio, video, text and $3 \mathrm{D}$ animations to give a smart narrative to their contents in local RTL (Right-to-Left) languages (such as Arabic, Persian and Urdu) as well.

The original text processing technology was developed keeping the Latin alphabet in consideration. However with greater dissemination of information technology and the focus shifting to other languages due to greater demand in these markets, subsequent technologies were developed for other languages like for instance Arabic, Japanese, Korean, Persian, and Hindi etc. Such adaptation requires work to be done on support for fonts, standardization etc., however a lot of work remains to be done with regards to addressing the idiosyncrasies of the Arabic language particularly its sister languages Persian, Urdu, Sindhi, Kashmiri and all that a major chunk of population in Asia and Africa speak. Wide scope is there for both open source as well as proprietary initiatives in this regard. Investors and corporate houses attention is needed in this regard.

\subsection{Standardization of Fonts and other linguistics tools}

Standardization of fonts as per Open Type Unicode specifications is one of the very important tasks for RTL (Right-ToLeft) languages. There are some fonts that are Unicode and Open Type features complaint, but they lack good design and aesthetics. A lot of text analysis features for data mining and other scientific purposes simply cannot be carried out on these fonts that do not comply with Unicode Standard. 


\section{Conclusion}

Digital technology in itself is value neutral however its utilization can be a double edged sword. Responsibility of using it wisely rest on the individual. So, instead of shying away from modern technology because of its some negative aspects we need to sit together and find workable solutions that can be embraced by the community. Wherein we can minimize the damage and maximize the benefits.

There's no doubt that the digital culture has opened up the whole new opportunities for young generations to engage with their peers around the world and share their thoughts knowledge and experiences without geographical boundaries in a manner that their forefathers could never have imagined.

\section{References:}

1. Ingram, M. (2012). "Death and Facebook: Blurring the Line Between Real and Virtual, Bloomberg Businessweek".

2. Jenkins, H. (1958). "Confronting the Challenges of Participatory Culture Media Education for the 21st Century".

3. Mesch, G. S. (2009). "The Internet and Youth Culture". (March 29, 2015): http://www.iasc-culture.org/THR/archives/YouthCulture/Mesch.pdf

4. Mitra, A. (2010). "Digital Communications From e-mail to the Cyber Community". 
5. Monroe, B. (2004). "Crossing the Digital Divide: Race, Writing, and Technology in the Classroom".

6. Manuel Castells, (2007) "Communication, Power and Counter-power in the Network Society"

7. McLuhan (1964) "Understanding Media: The Extensions of Man"

8. Sanford, S. (2007). "Civic Life in the Information Age".

9. Sansom, I. (2012, November Friday 9). "Can paper survive the digital age?". The Guardian.

10. الإعلام الجديد وضوابط جديدة.. حتى لا يصبح قوة من دون مسؤولية. (2012).

الشرق الأوسط. 